\title{
First report of Candidatus Phytoplasma aurantifolia (16SrII group) associated with Conocarpus erectus disease in Iran
}

\author{
Mohammad Azimi $^{1} \cdot$ Reza Farokhinejad $^{1} \cdot$ Mehdi Mehrabi-Koushki $^{1}$
}

Received: 4 April 2017 / Accepted: 30 May 2017 / Published online: 13 June 2017

(C) Australasian Plant Pathology Society Inc. 2017

\begin{abstract}
During 2015-16, the symptoms of little leaf, leaf roll and stem fasciation were observed on Conocarpus erectus trees in Ahvaz, southwestern Iran. Nested polymerase chain reaction with phytoplasma $16 \mathrm{~S}$ rDNA-specific primers detected the pathogen in the symptomatic plants. Both, the BLASTn search and phylogenetic analysis of the partial 16S rDNA sequence showed that Conocarpus erectus little leaf phytoplasma is a member of the $16 \mathrm{Sr}$ II group 'Candidatus Phytoplasma aurantifolia'.
\end{abstract}

Keywords Ahvaz $\cdot$ Buttonwood $\cdot$ Disease $\cdot$ Leaf roll

Buttonwood (Conocarpus erectus), is an evergreen shrub of the family Combretaceae native to forest ecosystem of Florida in North America. This shrub is planted as an ornamental plant in urban green-spaces including parks, boulevards and yards. The wood of buttonwood is durable and is used to make railroad sleepers, fuel, buildings, boats, and charcoal. Conocarpus erectus is a common ornamental plant in Khuzestan province in the southwest of Iran. This plant can tolerate the very severe heat of Khuzestan province where summer temperatures may reach $50{ }^{\circ} \mathrm{C}$ (unpublished data). This region has a desert climate (Köppen climate classification $B W h$ ) with long, very hot summers and mild, short winters. Some areas of this province, including Ahvaz and Dezful cities, are consistently

Mehdi Mehrabi-Koushki

mhdmhrb@scu.ac.ir; mhdmhrb@gmail.com

1 Plant Protection Department, Agriculture Faculty, Shahid Chamran University of Ahvaz, Khuzestan Province, Ahvaz, Iran amongst the hottest climates on the planet during the summer, with summer temperatures regularly at least $45{ }^{\circ} \mathrm{C}$, sometimes exceeding $50{ }^{\circ} \mathrm{C}$ with many sandstorms and dust storms common during the summer period.

In the last three years, phytoplasma-like symptoms of leaf roll, little leaf, stem fasciation and plant exudation on leaves (Fig. 1) were observed on buttonwood trees growing in urban parks and boulevards of Khuzestan province, southwestern Iran. During 2015-16, fifteen urban parks and boulevards in the two cities of Ahvaz and Dezful were evaluated and in each place, the buttonwood trees were visually inspected for the symptoms resembling phytoplasma diseases described above. Leaf samples and herbaceous branches from 15 symptomatic and three symptomless buttonwoods in fifteen inspected parks and boulevards were collected. The samples were packed in paper bags and transferred to the lab on ice. The leaf midribs, petioles and the parts of stem cambium were separated and freeze-dried into $50 \mathrm{ml}$ tubes capped with sterile gas (Freeze-Dryer, Alpha 1-2LD Plus, Christ). The samples were powdered in the mortar containing liquid nitrogen and stored in the $-20{ }^{\circ} \mathrm{C}$ freezer. Genomic DNA was extracted from $\sim 100 \mathrm{mg}$ of powdered tissues using a CTAB-based method as described by Maixner et al. (1995) with minor modifications. The lysates obtained from each sample were extracted two times by phenol: chloroform:isoamyl alcohol and chloroform:isoamyl alcohol, respectively. Total DNA was analyzed by the nested polymerase chain reaction assay, in which the partial regions of $16 \mathrm{~S}$ rDNA were amplified using two primer pairs of P1/P7 (Deng and Hiruki, 1991) and R16F2n/R16R2 (Gundersen and Lee, 1996). The nested PCR products were separated by electrophoresis in $1 \%$ agarose gels and the fragments of 
Fig. 1 The symptoms of Conocarpus erectus little leaf phytoplasma in a buttonwood tree growing in the campus of Shahid Chamran University of Ahvaz. a, leaf roll and little leaf. b, stem fasciation. c, plant exudation from the leaf edge
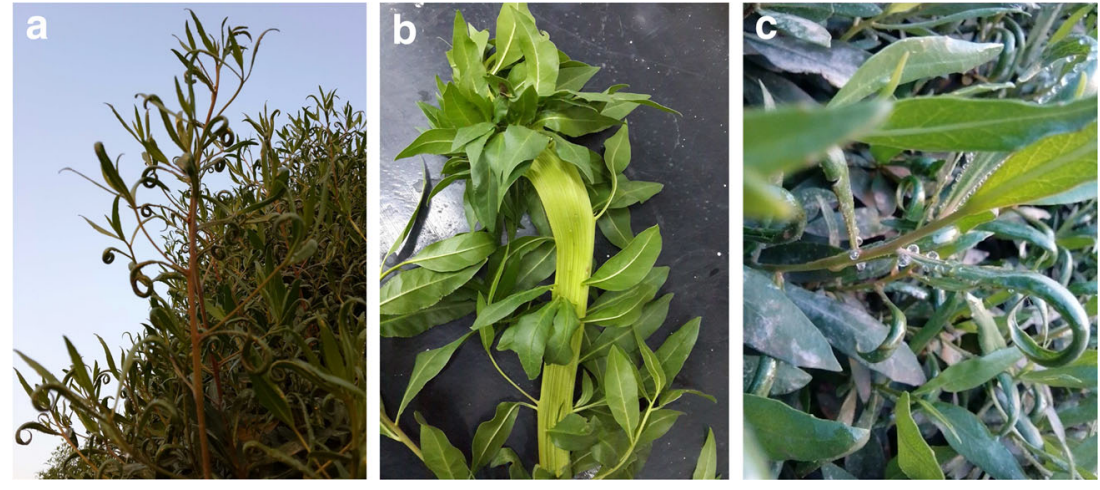

the expected size were excised and purified by GF-1 AmbiClean Kit (Vivantis, Malaysia) according to the manufacturer's instructions. The amplicons were directly sequenced in both directions by Macrogen Company. The Sequences were edited and assembled using BioEdit Sequence Alignment Editor v. 7.0.9.0 (Hall, 1999) and DNA Baser Sequence Assembeler v4 programs (2013, Heracle BioSoft, www.DnaBaser.com), respectively. The partial consensus $16 \mathrm{~S}$ rDNA sequences were compared to those of reference phytoplasmas by BLASTn search analysis. The $16 \mathrm{~S}$ rDNA sequences of three phytoplasma isolates detected from buttonwood and those of references from GenBank (as row data in Fig. 2) were aligned with Clustal $\mathrm{W}$ in MEGA version 6 (Tamura et al., 2013). A phylogenetic tree (Fig. 2) was constructed using the maximum likelihood algorithm under the TN93 + G + I model of the MEGA 6 software (Tamura et al., 2013).

Direct PCR using P1/P7 universal primers resulted in the expected size bands of approx. $1.8 \mathrm{~kb}$ from nine out of fifteen symptomatic plants; no product was obtained from any of the symptomless plants. The nested PCR using $\mathrm{R} 16 \mathrm{~F} 2 \mathrm{n} / \mathrm{R} 16 \mathrm{R} 2$ universal primers resulted in bands of approx. $1.2 \mathrm{~kb}$ suggesting the association of a phytoplasmal agent with the observed symptoms in buttonwood trees. The obtained sequences from both directions were assembled, and were identical for all nine samples. The partial consensus 16S rDNA of three isolates of Ahvaz-4, Ahvaz-10 and Dezful were deposited in GenBank (Accession No. KX088465, KY438206 and KY438207). BLASTn search analysis of the phytoplasma isolates showed that their $16 \mathrm{~S}$ rDNA sequences have $99 \%$ identity to the members of group 16SrII 'Candidatus Phytoplasma aurantifolia', i.e. 'Tylophora indica' little leaf yellowing phytoplasma (KF773149); Alfalfa phytoplasma and Alfalfa witches'-broom phytoplasma (KY449416, KT943970, KT943961, KY449418, KY449415 and KT943971); 'Chrysanthemum morifolium' Phytoplasma (KY488190, KX641012,
KX641009 and KX641008); 'Sesamum indicum' phyllody phytoplasma (KY547787); 'Vigna radiata' phyllody phytoplasma (KY439871); Brinjal little leaf phytoplasma (KX689254 and KX689253); 'Celosia argentea' flattened stem phytoplasma (KX671550 and KX641018) and 'Petroselinum crispum' witches'-broom phytoplasma (KU501295).

The sequence alignments of three phytoplasma isolates detected from buttonwood and those of references from GenBank including the outgroup taxon Acholeplasma_laidlawii_(U14905.1) were 1182 bp in length, including alignment gaps; of those characters $744 \mathrm{bp}$ were constant and $416 \mathrm{bp}$ were variable (150 bp were variable and parsimony uninformative and 266 bp were parsimony informative). The phylogenetic tree of the maximum likelihood analysis based on the consensus $16 \mathrm{~S}$ rDNA of reference and surveyed isolates are shown in Fig. 2. The topology of the phylogenetic tree showed that the phytoplasma isolates under study, Conocarpus erectus little leaf phytoplasma, clustered with the reference phytoplasma subgroup 16SrIID, 'Candidatus Phytoplasma aurantifolia' (Y10097) and generated a monophyletic clade with strong BS 99\% support.

In this study, only nine out of symptomatic plants showed the presence of phytoplasm out of the 15 diseased specimens that were surveyed. The failure to detect phytoplasma in six of symptomatic samples may be due to a low phytoplasma concentration or an uneven distribution within plant tissues. Based on highest sequence identity and close phylogenetic relationships, the phytoplasmal agent detected from buttonwood trees showing the symptoms of leaf roll, little leaf and stem fasciation in Ahvaz and Dezful were identified as isolates of $16 \mathrm{SrII}$ group phytoplasma, subgroup D ('Candidatus Phytoplasma aurantifolia'). The association of members of the 16SrII group phytoplasma with diverse symptoms in herbaceous and woody plants has been reported from different climates of the world in the last three decades (Bertaccini 
Fig. 2 Phylogenetic tree based on the 16S rDNA sequences of the Conocarpus erectus little leaf phytoplasma (isolates of Ahvaz4, Ahvaz-10 and Dezful) and reference sequences from GenBank. Accession numbers and Bootstrap values greater than $50 \%$ (expressed as percentages of 1000 replications) are shown in brackets and at the nodes, respectively. The tree was rooted with Acholeplasma laidlawii ATTC 23206 (U14905)

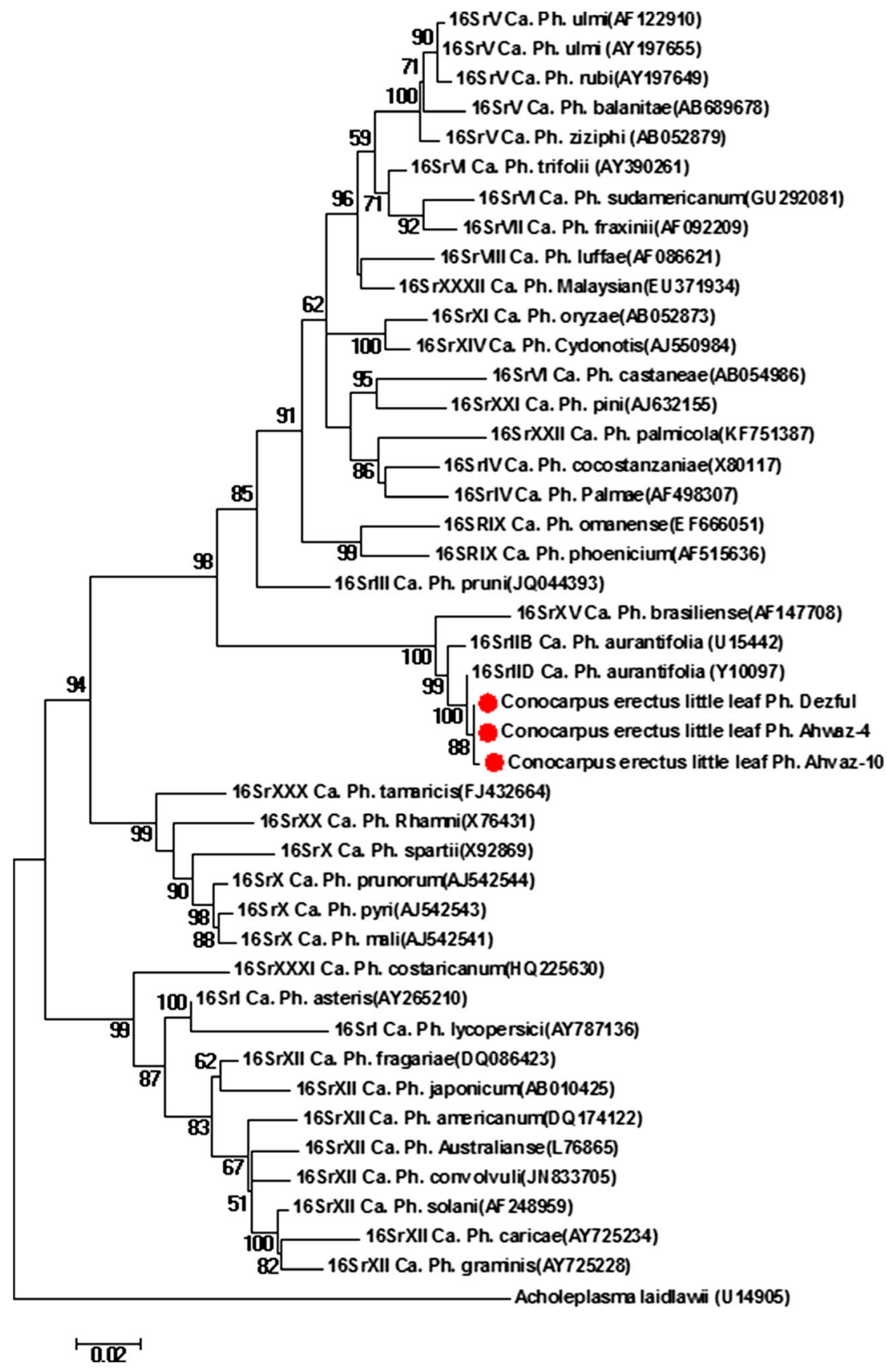

and Duduk, 2009; Bertaccini et al., 2014; https://www. ncbi.nlm.nih.gov). In recent years, the 16SrII-D subgroup strains of 'Candidatus Phytoplasma aurantifolia' were reported which are associated with different disease symptoms of plants in Iran, i.e. eggplant big bud (JX441321, JX483699 and JX483698), alfalfa witches'-broom (KT634120 and KT943971), pomegranate little leaf (KT265696), eucalyptus leaf roll (KX088462) and phyllody in broad bean, squash, cucumber and sesame (KP869129, KR822805, KR822804 and KT265706). To our knowledge based on GenBank records of phytoplasma (KX088465), this is the first report of a $16 \mathrm{SrII}$ phytoplasma infecting the trees of Conocarpus erectus throughout the world. The Conocarpus erectus little leaf phytoplasma is affecting approximately $3 \%$ of buttonwood trees in Ahvaz and Dezful. Previous studies indicated that phytoplasmas are plant pathogens related to devastating damage to several hundreds of plant species, including many economically important food, vegetable, and fruit crops; ornamental plants, timber and shade trees worldwide (Bertaccini et al., 2014), and therefore, the identification of Conocarpus erectus little leaf phytoplasma will contribute to improving the integrated disease management of buttonwood. 


\section{References}

Bertaccini A, Duduk B (2009) Phytoplasma and phytoplasma diseases: a review of recent research. Phytopathol Mediterr 48:355-378

Bertaccini A, Duduk B, Paltrinieri S, Contaldo N (2014) Phytoplasmas and phytoplasma diseases: a severe threat to agriculture. Am J Plant Sci 5:1763-1788

Deng S, Hiruki C (1991) Amplification of 16S rRNA genes from culturable and non-culturable mollicutes. J Microbiol Meth 14:53-61

Gundersen DE, Lee IM (1996) Ultrasensitive detection of phytoplasmas by nested-PCR assays using two universal primer sets. Phytopathol Med 35:144-151
Hall TA (1999) BioEdit: a user-friendly biological sequence alignment editor and analysis program for windows 95/98/NT. Nuc Acid Symp Ser 41:95-98

Maixner M, Ahrens U, Seemuller E (1995) Detection of the German grapevine yellows (Vergilbungskrankheit) MLO in grapevine, alternative hosts and a vector by a specific PCR procedure. Eur J Plant Pathol 101:241-250

Tamura K, Stecher G, Peterson D, Filipski A, Kumar S (2013) MEGA6: molecular evolutionary genetics analysis version 6.0. Mol Biol Evol $30: 2725-2729$ 